\title{
Pulmonary valve infective endocarditis with atrial septal defect and pulmonary valve disease - too coincidental to be true?
}

\author{
M. W. L. Smits · R. Tukkie · P. G. Meregalli - D. Robbers-Visser · P. T. G. Bot
}

Published online: 7 February 2020

(C) The Author(s) 2020

In this case we describe a 68-year-old male patient who presented with malaise after being treated for a urinary tract infection caused by enterococcus faecalis. The electrocardiogram showed atrial fibrillation and subsequent transthoracic echocardiography revealed a mobile structure on the pulmonary valve with an increased transpulmonary valve gradient (Fig. 1). Blood cultures were positive for enterococcus faecalis and PET-CT revealed F-18-fluorodeoxyglucose (FDG) uptake in the right ventricular outflow tract and lungs.

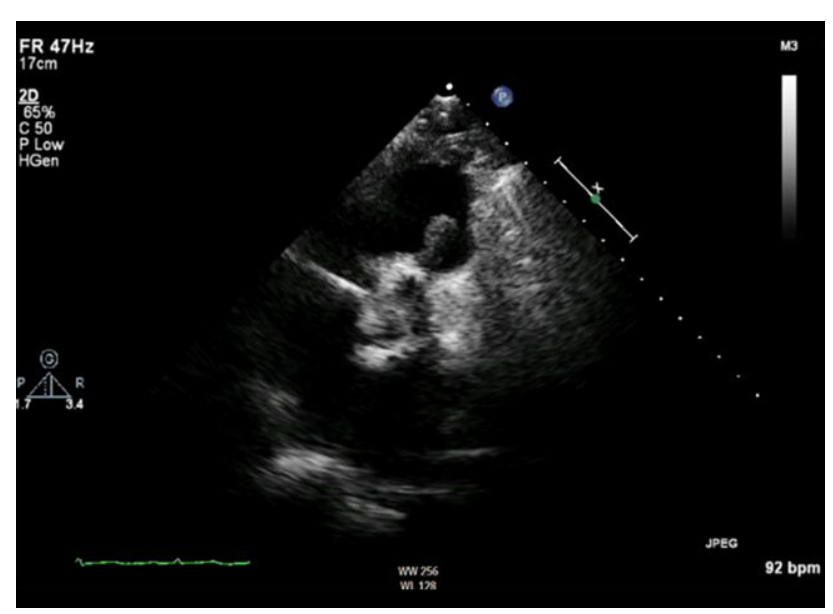

Fig. 1 TTE showing a mobile structure on the pulmonary valve. $T T$ transthoracic echocardiography

M. W. L. Smits · R. Tukkie · P. T. G. Bot $(\bowtie)$

Department of Cardiology, Spaarne Gasthuis, Haarlem, The Netherlands

pbot@spaarnegasthuis.nl

P. G. Meregalli · D. Robbers-Visser

Department of Cardiology, Amsterdam University Medical

Centers-location AMC, Amsterdam, The Netherlands

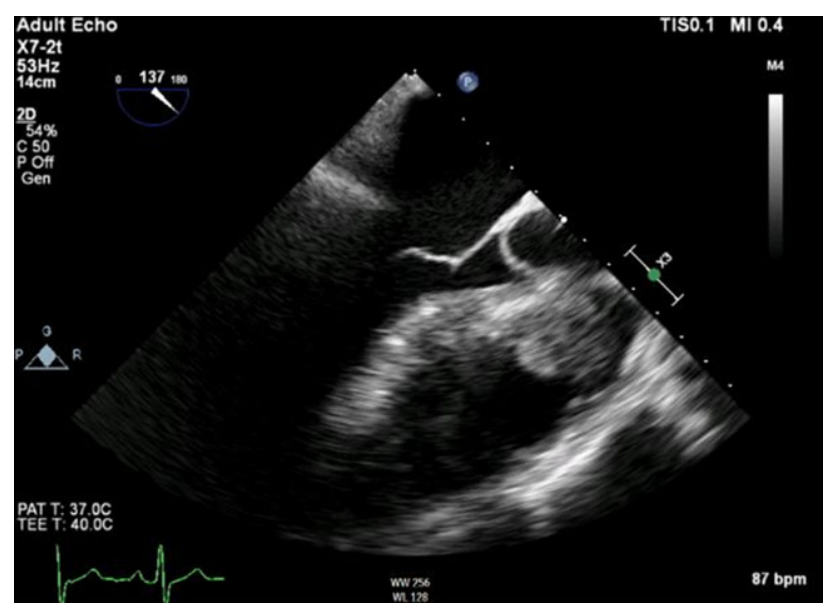

Fig. 2 TEE showing thickened pulmonary valve and atrial septal defect. TEE transoesophageal echocardiography

Transoesophageal echocardiography revealed a previously unknown small atrial septal defect type 2 with left-to-right shunt as well as a moderate pulmonary valve stenosis and severe regurgitation (Fig. 2).

In the majority of cases, right-sided infective endocarditis involves the tricuspid valve and is associated with intravenous drug use or the presence of pacemakers [1-3]. In this case, a type 2 atrial septal defect and a dysplastic pulmonary valve were observed. This case underscores the importance of thorough investigation of coexistent congenital heart defects in cases of right-sided infective endocarditis [4].

Open Access This article is licensed under a Creative Commons Attribution 4.0 International License, which permits use, sharing, adaptation, distribution and reproduction in any medium or format, as long as you give appropriate credit to the original author(s) and the source, provide a link to the Creative Commons licence, and indicate if changes were made. The images or other third party material in this article 


\section{Heart Beat}

are included in the article's Creative Commons licence, unless indicated otherwise in a credit line to the material. If material is not included in the article's Creative Commons licence and your intended use is not permitted by statutory regulation or exceeds the permitted use, you will need to obtain permission directly from the copyright holder. To view a copy of this licence, visit http://creativecommons.org/licenses/by/4.0/.

\section{References}

1. Vereckei A, Vándor L, Halász J, et al. Infective endocarditis resulting in rupture of sinus of Valsalva with a rupture site communicating with both the right atrium and right ventricle. JAm Soc Echocardiogr. 2004;17(9):995-7.

2. Moss R, Munt B. Injection drug use and right sided endocarditis. Heart. 2003;89(5):577-81.

3. Yuan SM. Right-sided infective endocarditis: recent epidemiologic changes. Int JClin Exp Med. 2014;7(1):199-218.

4. Das CK, Ete T, Dorjee R, et al. Atrial septal defect with pulmonary valve endocarditis-an unusual friendship. MOJ Clin Med Case Rep. 2017;6(2):42-3. 